\title{
THE VALIDATION OF THE LOGARITHMIC VELOCITY PROFILES ABOVE ROUGH-BED FLOWS
}

\author{
SHAHLA NASSRULLAH ${ }^{\left({ }^{*}\right)}$, ALEX STUBBS $^{(2)}$, THORSTEN STOESSER ${ }^{(3)}$ \\ \& CATHERINE A.M.E. WILSON ${ }^{(4)}$ \\ ${ }^{(1 *, 2,4)}$ Hydro-environmental Research Centre (HRC), \\ Cardiff University, Cardiff, United Kingdom \\ nassrullahsa@cardiff.ac.uk \\ (3) Department of Civil, Environmental and Geomatic Engineering, \\ University College London, London, United Kingdom
}

\begin{abstract}
Knowledge of rough-bed flows is important for river engineers and environmental scientists alike as most natural surface water flows are considered within the hydraulically rough flow regime. This study helps our understanding of flow characteristics above a rough gravel riverbed, which in-turn, affect fine sediment and nutrient transport which can have a large impact on aquatic organisms and the ecosystem at large. High velocity flows over rough beds result in increased turbulence intensity and contribute to the suspension of fine sediment. Therefore, the main aim of this study is to validate first-order turbulence statistics in the form of spatiallyaveraged streamwise velocity profiles of the flow over a highly-porous rough bed at intermediate relative submergence. The experiments were conducted under uniform flow conditions in Cardiff University's Hydraulics Laboratory using a narrow flume, $10 \mathrm{~m}$ long, $0.3 \mathrm{~m}$ wide, and $0.3 \mathrm{~m}$ deep, equipped with a bed of natural gravel with an average diameter of $20 \mathrm{~mm}$. A side looking Acoustic Doppler Velocimeter (ADV) was used to measure velocity profiles at 40 random locations within the sampling area. The results show that a logarithmic velocity profile is valid for rough-bed flows with a von Karman's constant of 0.41 and a Nikuradse equivalent sand roughness of between $1.5 \mathrm{~d}$ and $2 \mathrm{~d}$.
\end{abstract}

Keywords: Rough gravel riverbed, Acoustic Doppler Velocimeter (ADV), Rough surface turbulence, Logarithmic velocity profile, Hydraulically rough flow.

\section{INTRODUCTION}

Although much research has recently focused on flows above gravel riverbeds, there is a need for further investigation under flows with high roughness Reynolds number and intermediate relative submergence. For example, Bomminayuni et al. (2011) used Large Eddy Simulation (LES) numerical modelling techniques to analyse turbulent flow above a bed of uniform hemispheres. They showed that a roughness Reynolds number $\mathrm{K}^{+}$greater than 70 can be considered hydraulically rough and thus, within the fully rough turbulent flow regime.

Nikora et al. (2007) and Nikora et al. (2001) explore double-averaging methods (in space and time averaging) and (in time and space averaging) for instantaneous variables in order to define fluid hydraulic characteristics, parameters and variables. Nikora et al. (2007) highlighted that spatial averaging factors might be defined for area averaging above a plane parallel to the mean bed. After time-space averaging, the advection diffusion equation for passive scalars leads to a double averaged advection diffusion equation (Nikora, 2004), derived from the so called first order double-averaged momentum conservation and continuity equations developed by Nikora et al. (2007).

Mohajeri et al. (2015) studied flow characteristics above a gravel bed with intermediate relative submergence and found that the logarithmic law remains ambiguous for these conditions. They also found that the parameters of the logarithmic law rely upon the flow submergence. Interestingly, they suggest that the logarithmic law might still apply, but requires further investigation.

Gaudio et al. (2010) showed that relative submergence affects the evaluation of the von Karman constant. Coleman (1981) explored the velocity profiles of sediment-laden flows using the wake law and found that the wake coefficient, rather than $\mathrm{K}$, is influenced by sediment motion. Such findings contradict that found by Liu et al. (2016) who used a constant $\mathrm{K}$ value of 0.41 for all experiments.

Relative submergence is defined as the ratio of flow depth to roughness length scale, thus, the shape of the velocity profiles within the logarithmic layer depend upon the relative submergence (Koll 2006). The argumentation about the upper boundary of the logarithmic layer are not yet conclusive (Koll, 2006). Franca et al. (2008) carried out field measurements in the Venoge and Chamberonne rivers in Switzerland with a deployable ADVP to measure streamwise velocity profiles. The riverbed's consisted of coarse pebbles with 
relative submergences of $h / d_{50}=5.25$ and 5.96 , respectively. These rivers also had a bed roughness irregularity parameter of $\sigma_{b} / d_{50}=0.50$ and 0.66 , where $\sigma_{b}$ is the standard deviation of the bed elevations. Franca et al. (2008) surmised that despite the low $\mathrm{h} / \mathrm{d}_{50}$ ratio, there exists a section in the velocity profiles where a logarithmic law may describe the velocity distribution. Franca et al. (2008) noted that for the Chamberonne river, zero-plane displacement and roughness heights are outside of the predictable range presented by the literature. The reason for this might be because of the difficulties in locating a geometric parameter that can reliably distinguish the roughness of the bed, for example, low relative submergence.

The shape of the velocity profile over the interfacial sublayer for flows with high relative submergence (type I) and flows of intermediate relative submergence (type II) within the form-induced sublayer is not yet clear (Nikora; et al. 2007). Moreover, Pokrajac et al. (2007) noted that the turbulent boundary layer structure above a rough bed has received little attention compared with smooth beds. It should be noted from the literature that velocity profiles above rough beds are yet to be understood. Nakagawa et al. (1975) concluded that the dynamics of turbulence in the near bed region is the most complicated and interesting problem still to be solved due to incomplete measurements and should be studied further, together with the mechanism of turbulence generation.

Stoesser (2010) found that due to the variability of bed elevations, vortices separate and overlap with each other creating local recirculation regions behind exposed particles which increase in size dependent on the size of the particle itself. Stoesser (2010) also shows that not only does the global bed-shear stress increase, but so too does the thickness of the roughness layer.

Bomminayuni et al. (2011) showed that the spatially averaged wall normal turbulence intensity of a smooth bed case is less than that for a rough bed, meaning that roughness promotes mixing in the bed in the normal direction. Such roughness results in the convection of high momentum fluid away from the wall, thus spreading, or distributing, turbulence over a wider region and reducing the overall turbulence intensity (Bomminayuni et al. 2011; Stoesser, 2010). This is important for our understanding of how turbulence intensity and thus, bed roughness, contributes to the suspension of fine sediment (Grass 1982).

Therefore, this study will focus on the comparison between theoretically and experimentally derived velocity profiles with different values of von Karman's constant and Nikuradse equivalent sand roughness above a gravel riverbed. In doing so, this study aims to validate first-order turbulence statistics in the form of spatially-averaged streamwise velocity profiles of the flow over a highly-porous rough bed of intermediate relative submergence. Thus, showing that the logarithmic law can indeed be applied to rough-bed flows. Due to the limitations of this paper, the affect relative submergence has on the velocity profile will be explored in future work.

\section{METHODOLOGY}

The experiments were carried out in Cardiff University's Hydraulics Laboratory within the School of Engineering in a narrow recirculating flume, depicted in Figure 1. This flume has a length of $10 \mathrm{~m}$, width (B) of $0.3 \mathrm{~m}$, and depth $(\mathrm{H})$ of $0.3 \mathrm{~m}$, a maximum flow rate of $27 \mathrm{l} / \mathrm{sec}$, and a maximum velocity $(\mathrm{u})$ of $0.9 \mathrm{~m} / \mathrm{sec}$. A weir-controlled water depth at the channel outlet and a gauge point were used to measure the water depth and bed elevation. Uniform flow conditions were established for different flow cases with and without gravel by adjusting the tailgate for a given flowrate and the water surface was measured using a point gauge to ensure it was parallel with the flume bed.

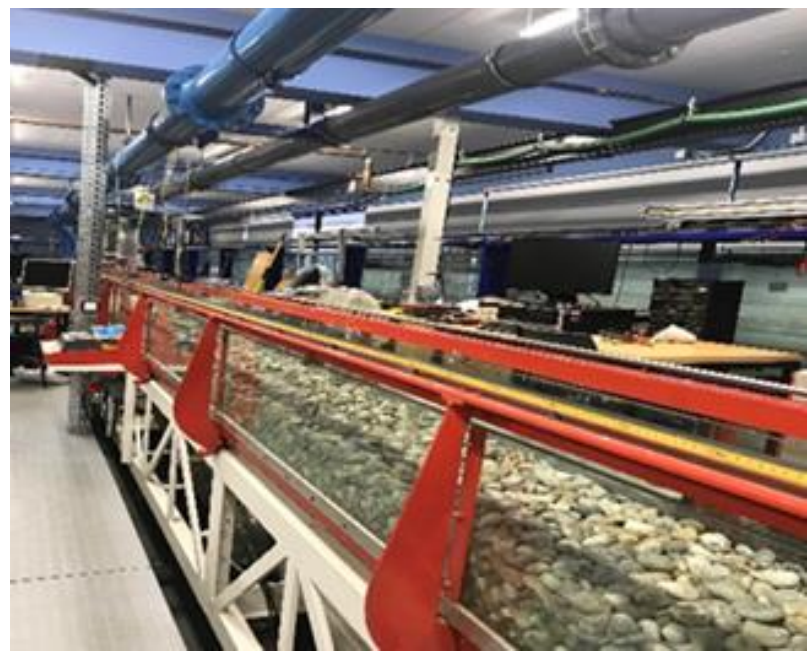

Figure 1. The narrow flume used in this study. 
The flume bed was covered in gravel with an average diameter of $20 \mathrm{~mm}$ and placed to a total depth of 120 $\mathrm{mm}$. The grain size was chosen as it represents that found in salmonid redds in UK rivers. Female salmonids in Southern England, North-Eastern England and South-Western Wales have been found to prefer to spawn in medium sized gravel of diameter between $20 \mathrm{~mm}$ and $30 \mathrm{~mm}$ (Crisp and Carling, 1989).

The gravel had a bulk Saturated Surface Dry (SSD) specific gravity, or GsSD, of 2.62 and the bed porosity was calculated using the relationship between void volume and total volume (Stephenson, 1979) and was found to be $38 \%$.

A point gauge was used to measure the topography of the bed elevations within the bed study area between $4 \mathrm{~m}$ and $6.8 \mathrm{~m}$ from the inlet to allow comparison with that of a natural riverbed. The standard deviation of the bed elevations $\sigma_{b}$ was found as $7.83 \mathrm{~mm}$, and in the same manner as (Stubbs et al. 2018; Nikora et al. 2001; and Stoesser, 2010), a roughness geometry function $A\left(z_{b}{ }^{\prime}\right)$ was calculated. Figure 2 shows $A\left(z_{b}{ }^{\prime}\right)$ which is the cumulative probability distribution of the surface bed elevations against a function of the fluctuations in surface elevation $\left(\mathrm{zb}_{\mathrm{b}}\right)$. As shown in Figure 2, the distribution of the surface gravel elevations is remarkably well fitted to that of both water-worked and un-worked natural gravel riverbeds observed by Nikora et al. (2001).

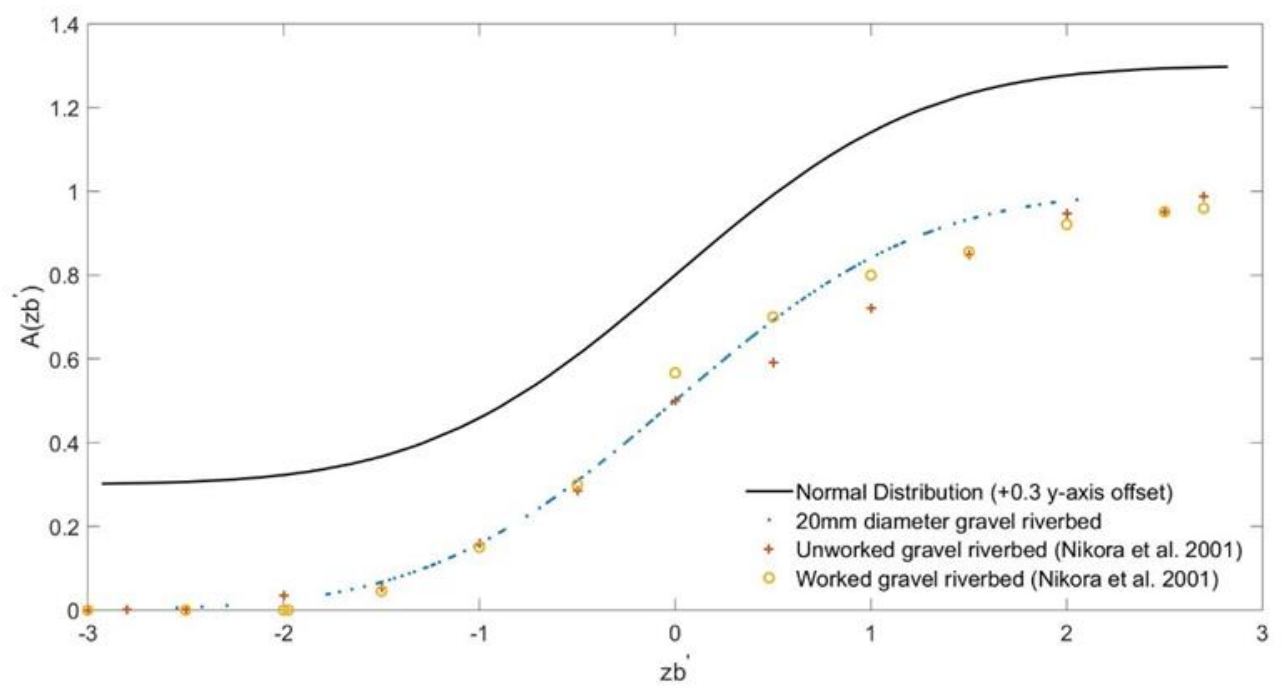

Figure 2. Roughness geometry function $A\left(z^{\prime}\right)$ as a function of the fluctuation in surface elevation $(\mathrm{zb})$.

Two experiments were carried out in the flume and Table 1 lists the hydraulic conditions for the experiments where $\mathrm{Q}$ is the discharge, $\mathrm{H}$ is the flow depth, Ubuk is the average velocity, $\mathrm{Fr}$ is the Froude number, $\mathrm{Re}$ is the Reynolds number, $\mathrm{K}^{+}$is roughness Reynolds number as explored by Pokrajac et al. (2007) where, $\mathrm{K}^{+}=\mathrm{U}^{*} \mathrm{~K} / v$ in which $\mathrm{K}$ is any dimensional variable linked with the roughness size (Perry and Joubert 1963), ob was used in this study in a similer fashion to Grass (1971) and $v$ is water kinematic viscosity, $\mathrm{H}_{0} / \sigma_{b}$ is the relative submergence where, $H_{0}$ is the maximum flow depth where, $H_{0}=H+\sigma_{b}, \mathrm{~T}$ is bed shear stress, $R_{T}$ is bed Reynolds number, $\mathrm{n}$ is manning number.

Table 1. Hydraulic conditions for experimental run's 1 and 2.

\begin{tabular}{llllllllllllll}
\hline Run & $\begin{array}{l}\mathrm{Q} \\
(\mathrm{L} / \mathrm{s})\end{array}$ & $\begin{array}{l}\mathrm{H} \\
(\mathrm{cm})\end{array}$ & $\begin{array}{l}\mathrm{U}_{\text {bulk }} \\
(\mathrm{cm} / \mathrm{s})\end{array}$ & $\begin{array}{l}\mathrm{Fr} \\
(-)\end{array}$ & $\begin{array}{l}\mathrm{Re} \\
(-)\end{array}$ & $\begin{array}{l}\mathrm{K}^{+} \\
(-)\end{array}$ & $\begin{array}{l}\mathrm{H}_{0} / \sigma_{\mathrm{b}} \\
(-)\end{array}$ & $\begin{array}{l}\mathrm{T} \\
(\mathrm{N} / \mathrm{m} 2)\end{array}$ & $\begin{array}{l}\mathrm{U}^{*} \\
(\mathrm{~cm} / \mathrm{s})\end{array}$ & $\begin{array}{l}\mathrm{Re}_{T} \\
(-)\end{array}$ & $\begin{array}{l}\mathrm{S} \\
(-)\end{array}$ & $\begin{array}{l}\mathrm{n} \\
(-)\end{array}$ & $\begin{array}{l}\mathrm{B} / \mathrm{H} \\
(-)\end{array}$ \\
\hline 1 & 4.00 & 7.50 & 17.50 & 0.20 & 11,527 & 186 & 10.58 & 0.65 & 2.7 & 2,704 & 0.001 & 0.025 & 4.0 \\
2 & 6.04 & 9.20 & 21.90 & 0.23 & 17,674 & 206 & 12.75 & 0.91 & 3.0 & 3,329 & 0.001 & 0.021 & 3.3 \\
\hline
\end{tabular}

For run 1 , the velocity profiles were measured at 40 randomly selected points within an area $5.5 \mathrm{~m}$ to $6 \mathrm{~m}$ from the inlet of flume and between $125 \mathrm{~mm}$ and $150 \mathrm{~mm}( \pm 0.05 \mathrm{~mm})$ from the flume wall, where the flow was fully developed and unaffected by the influence of the side walls. A side looking Acoustic Doppler Velocimeter (ADV), manufactured by Nortek AS, was used to measure velocities profiles and its position moved in the vertical direction, z, using a stepper motor. Six data points, each $3 \mathrm{~mm}( \pm 0.05 \mathrm{~mm})$ apart were taken in the vertical direction for each of the 40 profiles.

To further understand the behavior of the velocity profile over a wider region, for run 2, measurements were taken in a grid-like pattern every $0.3 \mathrm{~m}( \pm 0.05 \mathrm{~mm})$ in the section between $4 \mathrm{~m}$ and $6.8 \mathrm{~m}$ from the inlet. Again, to avoid any influence the side wall might have had, measurements were taken between $125 \mathrm{~mm}$ and $150 \mathrm{~mm}$ 
$( \pm 0.05 \mathrm{~mm})$ from the flume wall. However, for run 2, seven data points, each $5 \mathrm{~mm}( \pm 0.05 \mathrm{~mm})$ apart were taken in the vertical direction for each profile. The first velocity profile was measured at $x=-0.4 \mathrm{~m}$, as shown in Figure 3 , by direct velocity measurement. The frequency of the ADV was $25 \mathrm{~Hz}$, the Signal Noise Ratio (SNR) was more than $15 \mathrm{db}$ and the correlation more than 70 for all runs. Measurements were carried out for 5 minutes at each elevation for both experimental runs. The ADV data was analysed using Velocity Signal Analyser Software (Jesson 2015).

The relative submergence for run 1 was found to be 10.58, as shown in Table 1. Therefore, the flow was classified as intermediate relative submergence or flow Type 2 (Nikora et al. 2001; Nikora, 2008). For run 2 the relative submergence was found to be 12.75, as shown in Table 1, and the flow can also be categorized as intermediate relative submergence or Type 2 (Nikora et al. 2001; Nikora, 2008).

The shear velocity, $\mathrm{U}^{*}$, in Table 1 was found using water depth instead of the hydraulic radius (Shvidchenko and Pender, 2000) as side wall influences could be ignored since measurements were taken in sections where the side wall had no effect, as previously discussed. Thus, Eq. [1] is not only convenient, but appropriate for use in this study to obtain shear velocity.

$$
\mathrm{U}^{*}=\sqrt{\mathrm{gHS}}
$$

where, $g$ is gravitational acceleration, and $S$ is bed slope.

In this study, the theoretical velocity profiles were found by applying Eq. [2] (Nezu and Nakagawa, 1993).

$$
\frac{\overline{\mathrm{u}}}{\mathrm{u}^{*}}=\frac{1}{\mathrm{\kappa}} \ln \left(\frac{\mathrm{z}}{\mathrm{k}_{\mathrm{s}}}\right)+8.5
$$

where, $\bar{u}$ is the instantaneous mean velocity at a height $y$ above the bed level, $\kappa$ is the von Karman's constant equal to 0.4 for clear water, $\mathrm{k}_{\mathrm{s}}$ is the Nikuradse equivalent sand roughness, and 8.5 is a constant of integration for rough bed surfaces.

\section{RESULTS AND DISCUSSION}

\subsection{VELOCITY PROFILES}

The theoretical velocity profile calculated using Eq. [5] was compared with that measured for both runs as shown in Figure's $3 a$ and b. Figure 3a illustrates longitudinal velocity normalised with $U^{*}$ versus $Z^{+}=\left(\mathrm{z}_{0} \mathrm{U}^{*} / v\right)$, where $\mathrm{Z}^{+}$is the vertical direction and the + superscript indicates wall units, $5.579 \mathrm{~m}$ and $5.638 \mathrm{~m}$ from the inlet as well as the spatially averaged velocities (averaging in time and then in space) for the 40 randomly selected velocity profiles for run 1 . As shown by Figure 4a, the measured velocity profiles agree well with Eq. [5] when $\kappa$, von Karman's constant, equals 0.41 for clear water and ks, the Nikuradse equivalent sand roughness, equals 2d. In addition, Figure 4b shows a comparison between Eq. [5] and measurements taken when $\mathrm{x}=-0.4 \mathrm{~m}, 0.8$ $\mathrm{m}$, and $2.6 \mathrm{~m}$ for run 2. As shown in Figure $4 \mathrm{~b}$, the measurements similarly agree well with Eq. [5] when $\kappa$ equals 0.41 , however, for run $2, \mathrm{ks}_{\mathrm{s}}$ equals $1.5 \mathrm{~d}$. Thus, the applicable range of $\mathrm{ks}_{\mathrm{s}}$, due to variations in the instantaneous mean velocity and the shear velocity in runs 1 and 2 is between $1.5 \mathrm{~d}$ and $2 \mathrm{~d}$ and was calculated using the methodology outlined by Bridge and Bennett (1992). Therefore, agreeing with the postulation that the logarithmic velocity profile might still be valid, even for type II rough-bed flows, so long as the displacement of the zero velocity plane within the gravel bed, the von Karman's constant $\mathrm{K}$ and the log-law limits are modulated depending upon the bed geometry and the flow conditions (Koll, 2006; Gaudio et al. 2010; Nikora, 2008). 

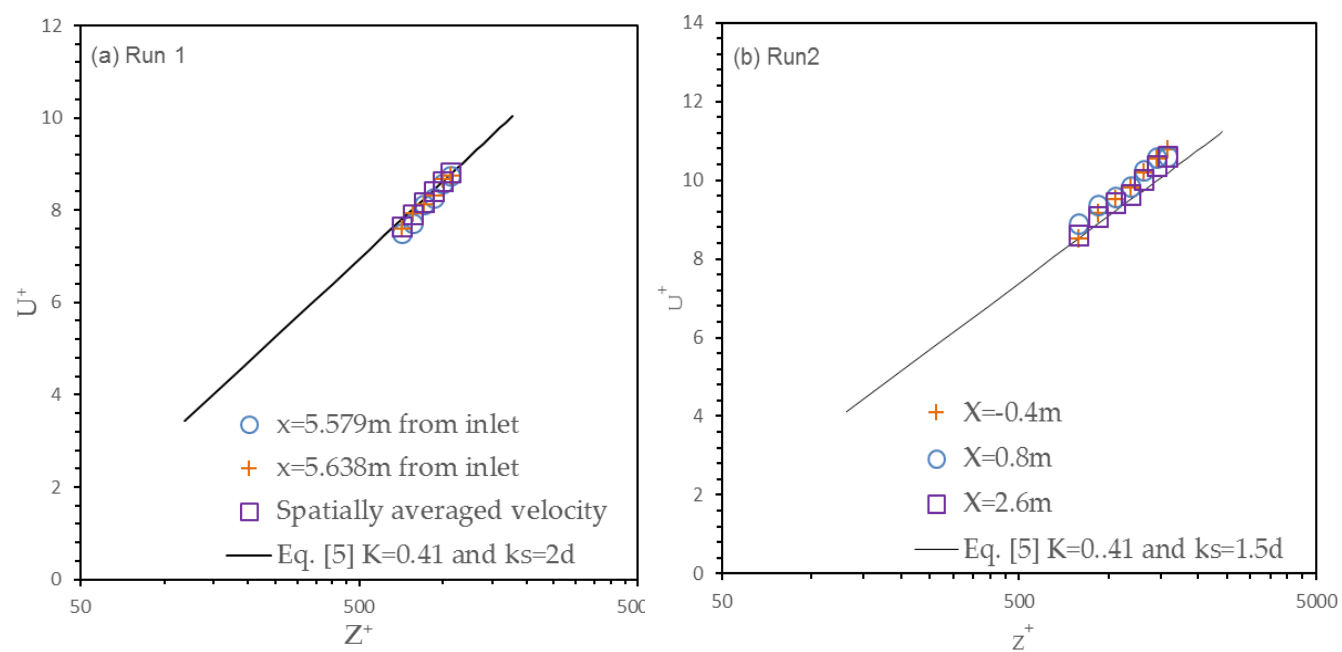

Figure 3. Longitudinal velocity normalised with $U^{*}$ versus $Z^{+}$for both (a) run 1 and (b) run 2.

\subsection{TURBULENCE INTENSITY}

Nezu and Nakagawa (1993) found that horizontal turbulence intensity distribution is larger than vertical turbulence intensity distribution, while transverse turbulence intensity is somewhere in-between, as described by the following equations:

$$
\begin{aligned}
\mathrm{u}^{\prime} & =\mathrm{D}_{1} \mathrm{e}^{-\lambda_{1}\left(\frac{z_{0}}{\mathrm{H}}\right)} \\
\mathrm{v}^{\prime} & =\mathrm{D}_{2} \mathrm{e}^{-\lambda_{2}\left(\frac{z_{0}}{\mathrm{H}}\right)} \\
\mathrm{w}^{\prime} & =\mathrm{D}_{3} \mathrm{e}^{-\lambda_{3}\left(\frac{z_{0}}{\mathrm{H}}\right)}
\end{aligned}
$$

where, $u^{\prime}, v^{\prime}$, and $w^{\prime}$ are the Root Mean Square (RMS) values of velocity fluctuations in the longitudinal, transverse and vertical directions respectively, and $\lambda_{1}, \lambda_{2}, \lambda_{3}, D_{1}, D_{2}$, and $D_{3}$ are experimental constants. All $\lambda$ values are equal to 1 and D1, D2 and D3 are equal to $2.3,1.63$, and 1.27 respectively.

Figure 4. shows turbulence intensity as a spatial average of the RMS values of the velocity fluctuations in the longitudinal, transverse, and vertical directions normalised with shear velocity for run 1 and compared with the result of Eq's. [3], [4], and [5].

The turbulence intensity measurements in the longitudinal direction agree well with Eq. [3] for all sections. However, measurements in the transverse direction are different to that provided by Eq. [4] for all sections and similarly in the vertical direction compared to the results of Eq. [5] for all sections. Tennekes et al. (1972) found that $u$ ' has a direct correlation to large-scale eddies which predominate turbulence production. Nakagawa et al. (1975) added that $v^{\prime}$ and $w^{\prime}$ poorly depend upon roughness; this might be because they contribute little to turbulence production. Otherwise, turbulent energy re-distribution may tend towards being isotropic as macroscale eddies decay due to the porosity (Nezu 1977). 


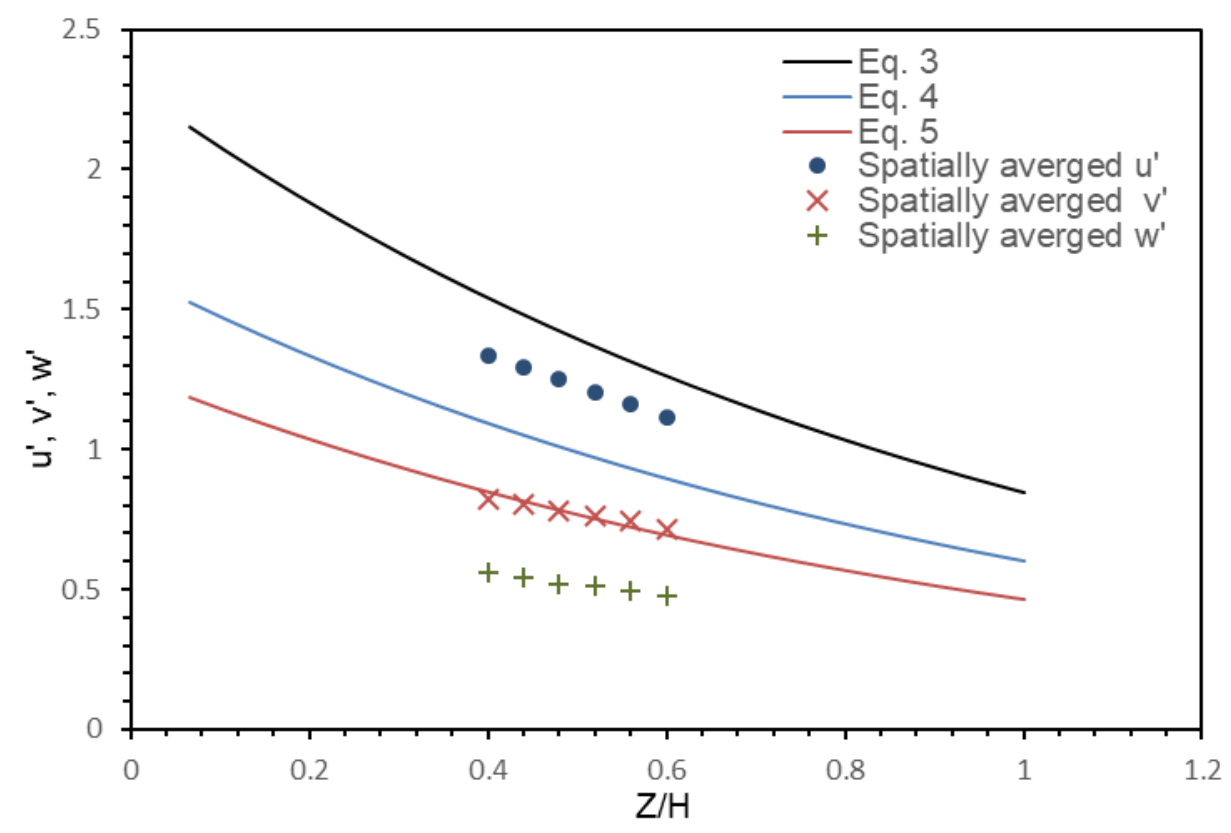

Figure 4. Turbulence intensity versus normalised vertical distance for run 1.

Figure 5 shows a comparison between the $u^{\prime}, v^{\prime}$, and $w^{\prime}$ values obtained from Eq's. [3], [4], and [5] and measurements taken at the center of the flume when $x=-0.4 \mathrm{~m}, 0.8 \mathrm{~m}$, and $2.6 \mathrm{~m}$ versus vertical distance normalised with water depth for run 2. Similarly to the results of run 1, $u^{\prime}$ measurements agree well with Eq. [3] for all sections, as shown in Figure 4. Equally like in run 1, $v^{\prime}$ measurements deviate from Eq. [4] and $w^{\prime}$ measurements are very different compared with Eq. [5] for run 2. Tominaga and Nezu (1992) showed that turbulence intensity normalized with shear velocity reduces from the usual universal function close to the wall in the case of supercritical flows and that peak $u^{\prime}$ is related to the shear velocity. However, turbulence intensity decreases near the top of the roughness elements with increasing distance from the wall. Thus, the turbulence intensity profile is distinguished by a minimal evenly distributed variability as the distance from the wall increases (Carollo et al. 2005).

Nezu (1977) suggested that $D_{1}$ should equal 2.3 and $\lambda_{1}$ should equal 1 for smooth walled open channel flows. Wang et al. (1993) showed that streamwise turbulence distribution intensity is highly reliant upon relative submergence and when relative submergence is greater than 4 , $D_{1}$ should equal 2.14 and $\lambda_{1}$ should be set to 0.8. Nakagawa et al. (1975) summarised that the intensity u' and the mean eddy size decrease with increased roughness. Thus, it can be deduced that the redistribution of turbulent energy in the flow above a rough wall might develop more quickly and tend towards an isotropic case than that above a smooth wall. Nakagawa et al. (1975) also showed that the impact of roughness varies with $\mathrm{K}^{+}$and the variance in turbulence intensities close to the bed becomes flatter whilst at a point far away from the bed, intensities are independent of roughness. 


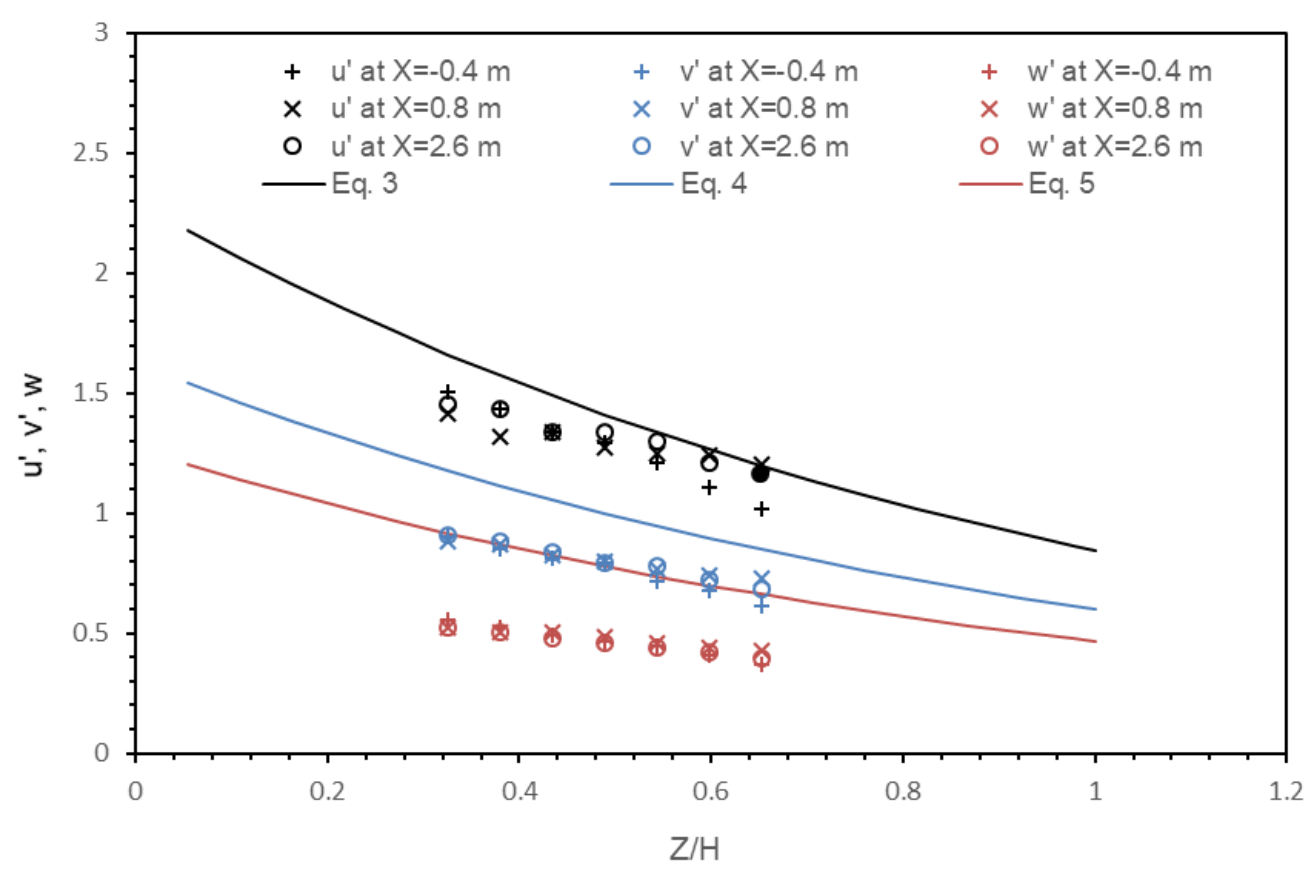

Figure 5. Turbulence intensity versus normalised vertical distance for run 2 at the center of the flume.

\section{CONCLUSIONS}

Two experimental runs were undertaken in a recirculating narrow flume $10 \mathrm{~m}$ long, $0.3 \mathrm{~m}$ wide, and $0.3 \mathrm{~m}$ deep under uniform flow conditions. $20 \mathrm{~mm}$ diameter gravel was spread uniformly over the length of the flume bed with the experimental sampling area between $4 \mathrm{~m}$ and $6.8 \mathrm{~m}$ from the inlet where the flow was considered fully developed. The gravel within the sample region had a porosity of $38 \%$. However, by accounting for the true extent of what can be considered as part of the channel, up to $0.25 \mathrm{~d}$ from the peak of the gravel bed, the porosity and void ratio were adjusted to $35.8 \%$ and 0.56 respectively. A gauge-point was used to collect water depth and gravel bed surface topography measurements and a side-looking ADV was used for velocity data collection. The velocity profiles and turbulence intensity were analysed and compared against that theoretically derived by Nezu and Nakagawa (1993); allowing parameter calibration. The measurements were taken in the range $700<$ $\mathrm{Z}^{+}<1600$ for both runs. The following are the main conclusions from the experiments conducted in this study:

1. The standard deviation of the gravel surface elevation within the experimental sampling area was calculated as $7.83 \mathrm{~mm}$. This agrees well with the literature for unworked and water-worked gravel riverbeds.

2. The grain size and porosity of the gravel within the sampling area is in good agreement with that found in the literature and is therefore comparable with a natural riverbed.

3. The theoretical logarithmic velocity profiles fit well with measurements above rough-bed flows at intermediate relative submergence in both experimental runs. This was achieved by adjusting the von Karman's constant to 0.41 and the Nikuradse equivalent sand roughness to between $1.5 \mathrm{~d}$ and $2 \mathrm{~d}$. Thus, theoretical logarithmic velocity profiles above rough-bed flows are valid in the range $700<Z+<1600$ and shear velocity is affected by the Nikuradse equivalent sand roughness

4. Analysis of the turbulence intensity in the streamwise direction showed good agreement between the measurements and theory. However, both the vertical and transverse intensity were found to be significantly lower than the theoretically proposed values.

\section{ACKNOWLEDGEMENTS}

This work was supported by the Engineering and Physical Sciences Research Council in the UK via grant EP/L016214/1 awarded for the Water Informatics: Science and Engineering (WISE) Centre for Doctoral Training, which is gratefully acknowledged. The author Shahla Nassrullah would also like to acknowledge the financial support provided by the Iraqi Ministry of Higher Education and Scientific Research and Middle Technical University for the duration of this study. 


\section{REFERENCES}

Bomminayuni, S. et al. 2011. Turbulence Statistics in an Open-Channel Flow over a Rough Bed. Journal of Hydraulic Engineering 137(11), pp. 1347-1358. doi: 10.1061/(ASCE)HY.1943-7900.0000454.

Bridge, J.S. and Bennett, S.J. 1992. A model for the entrainment and transport of sediment grains of mixed sizes, shapes, and densities. Water Resources Research 28(2), pp. 337-363. doi: 10.1029/91WR02570.

Carollo, F.G. et al. 2005. Analyzing turbulence intensity in gravel bed channels. Journal of Hydraulic Engineering 131(12), pp. 1050-1061. doi: 10.1061/(ASCE)0733-9429(2005)131:12(1050)

Coleman, N.L. 1981. Velocity profiles with suspended sediment. Journal of Hydraulic Research 19(3), pp. 211-229.

Crisp, D.T. and Carling, P.A. 1989. Observations on siting, dimensioins and structure of salmonid redds. Journal of Fish Biology 34, pp. 119-134. doi: 10.1111/j.1095-8649.1989.tb02962.x.

Franca, M.J. et al. 2008. Parameterization of the logarithmic layer of double-averaged streamwise velocity profiles in gravel-bed river flows. Advances in Water Resources 31(6), pp. 915-925. doi: 10.1016/j.advwatres.2008.03.001.

Gaudio, R. et al. 2010. Non-universality of von Kármán's K in fluvial streams. Journal of Hydraulic Research 48(5), pp. 658-663. doi: 10.1080/00221686.2010.507338.

Grass, A.J. 1971. Structural features of turbulent flow over smooth and rough boundaries. Journal of Fluid Mechanics 50(2), pp. 233-255.

Grass, A.J. 1982. The influence of boundary layer turbulence on the mechanics of sediment transport. Proc of Euromech 156, Mechanics of Sediment Transport. Rotterdam: AA Balkema. 1983. , pp. 3-17.

Jesson, M. 2015. MAJ 's Velocity Signal Analyser Installation and User Guide v1 . 5 . 46 ( ) Copyright 20132015 Michael Jesson.

Koll, K. 2006. Parameterisation of the vertical velocity profile in the wall region over rough surfaces. In: Proceedings of the International Conference on Fluvial Hydraulics, River Flow, edited by R. M. L. Ferreira et al.Taylor and Francis, London., pp. 163-172.

Liu, D. et al. 2016. Quantification of the bed load effects on turbulent open-channel flows. Journal of Geophysical Research: Earth Surface 121(4), pp. 767-789.

Mohajeri, S.H. et al. 2015. The structure of gravel-bed flow with intermediate submergence: A laboratory study. Water Resources Research 51(11), pp. 9232-9255.

Nakagawa, H. et al. 1975. Turbulence of open channel flow over smooth and rough beds. In: Proceedings of the Japan Society of Civil Engineers., pp. 155-168.

Nezu, I. 1977. Turbulent structure in open-channel flows. English translation of the Japanese dissertation of lehisa Nezu.

Nezu, I. et al. 2004. Turbulence Characteristics and Interaction between Particles and Fluid in Particle-Laden Open Channel Flows. Journal of Hydraulic Engineering 130(10), pp. 988-1001.

Nezu, I. and Nakagawa, H. 1993. Turbulence in open channels. IAHR/AIRH Monograph. Balkema, Rotterdam, The Netherlands

Nikora, V. et al. 2001. Spatially averaged open-channel flow over rough bed. Journal of Hydraulic Engineering 127(2), pp. 123-133.

Nikora, V. et al. 2007. Double-Averaging Concept for Rough-Bed Open-Channel and Overland Flows : Theoretical Background. Journal of Hydraulic Engineering 133(8), pp. 873-883.

Nikora, V. 2008. Hydrodynamics of gravel-bed rivers: scale issues. In Gravel Bed Rivers VI: From Process Understanding to River Restoration, edited by H. Habersack, H. Piegay, and M. Rinaldi, Elsevier, Amsterdam, Netherlands. doi: 10.1016/S0928-2025(07)11113-5.

Nikora, V.I. 2004. Spatial averaging concept for rough-bed open-channel and overland flows. Proc., of the 6th Int. Conf. on Hydro- Science and Engineering (CD-ROM), Brisbane.

Perry, B.A.E. and Joubert, P.N. 1963. Rough-wall boundary layers in adverse pressure gradients. Journal of Fluid Mechanics 17(2), pp. 193-211.

Pokrajac, D. et al. 2007. Quadrant analysis of persistent spatial velocity perturbations over square-bar roughness. Experiments in Fluids 42(3), pp. 413-423. doi: 10.1007/s00348-006-0248-0.

Stoesser, T. 2010. Physically Realistic Roughness Closure Scheme to Simulate Turbulent Channel Flow over Rough Beds within the Framework of LES. 136(10), pp. 812-819.

Stubbs, A. et al. 2018. Developing an Approximation of a Natural , Rough Gravel Riverbed Both Physically and Numerically. Geosciences 8(12), p. 449. doi: 10.3390/geosciences8120449.

Tennekes, $\mathrm{H}$. et al. 1972. A first course in turbulence. MIT press.

Tominaga, A. and Nezu, lehisa 1992. Velocity profiles in steep open-channel flows. Journal of hydraulic Engineering 118(1), pp. 73-90.

Wang, J. et al. 1993. The effects of bed roughness on the distribution of turbulent intensities in open-channel flow. Journal of Hydraulic Research 31(1), pp. 89-98. 